\title{
O PROCESSO DE ALFABETIZAÇÃO ESCOLAR NUMA
} PERSPECTIVA CRÍTICA ${ }^{1}$

\section{Sérgio Antônio da Silva Leite Cíntia Wolf do Amaral}

\section{Resumo}

A presente pesquisa tem como objetivo descrever as características do processo de alfabetização escolar desenvolvido numa perspectiva crítica. Organizou-se uma amostra selecionada composta por quatro educadores que apresentavam uma concepção de alfabetização considerada moderna, de acordo com critérios previamente definidos. Através de entrevistas recorrentes, coletaram-se relatos verbais visando identificar como o processo de alfabetização escolar pode colaborar com a formação do cidadão crítico. A análise final dos dados possibilitou identificar quatro conjuntos temáticos, por sua vez desdobrados em categorias e sub-categorias: caracterização do cidadão crítico; papel da escola na formação do cidadão crítico; crítica às práticas pedagógicas tradicionais; princípios teórico-metodológicos do processo de alfabetização escolar numa perspectiva crítica.

\section{Palavras-chave}

Alfabetização crítica; Alfabetização e cidadania; Leitura/escrita

\begin{abstract}
This research aimed to describe the characteristics of the literacy process, developed in a critical perspective. It was planned a selected sample with four educators who maintained a modern literacy concept, according to previous criterion. Data were collected by recurrent interviews, aiming to identify the relations between the school literacy process and critical citizenchip. The analysis of verbal reports identified four thematic groups: the characteristics of critical citizenchip; the role of the school in critical student development; the analysis of traditional educational practices; the theoritical and methodological principles of school literacy process in a critical perspective.
\end{abstract}

\section{Key-words}

Critical literacy; Literacy and citizenchip; Reading/writing

\footnotetext{
${ }^{1}$ Pesquisa realizada com o apoio da FAPESP
} 


\section{INTRODUÇÃO}

Atualmente, aceita-se que o processo de alfabetização é inseparável de seu contexto histórico-social. Para COOKGUMPERZ (1991), “(...) a alfabetização não pode ser julgada separadamente de alguma compreensão das circunstâncias sociais e tradições históricas específicas que afetam o modo como esta capacidade enraiza-se numa sociedade” (p. 29).

Durante este século, com a escolarização em massa, a alfabetização tornou-se uma prática descontextualizada pois passou a ser vista como “(...) uma disciplina formal de raciocínio letrado que toma a forma de um conjunto de habilidades técnicas" (COOK-GUMPERZ, 1991: p. 56) que deveria ser ensinada à população. Essa visão retrata os fundamentos de um modelo tradicional de educação que se baseia no papel dominante do professor como um transmissor de conhecimentos e informações, acreditando-se que a aprendizagem se dá através da memorização de modelos dados, não dependente diretamente das condições de ensino.

Nesta concepção de educação, a alfabetização é vista como um processo que se desenvolve a nível individual, desvinculada de seus usos sociais: um processo no qual a linguagem escrita é considerada o espelho da linguagem oral, em que o aluno deve aprender a codificar fonemas em grafemas (escrita) e grafemas em fonemas (leitura). Nesta perspectiva, a decifração e a dominação do código (processo mecânico) são entendidas como os aspectos centrais do processo, acarretando como consequiência a ênfase na preocupação com o erro ortográfico e a descontextualização da própria atividade de leitura e escrita.

Um dos efeitos da escolarização, segundo GRAFF (1991), foi a super valorização da alfabetização, desvinculando-a da análise da ideologia, da cultura e da consciência. Definida apenas como domínio do código e de técnicas, a alfabetização era considerada "neutra", o que GRAFF caracteriza como "mito das técnicas objetivas". Além disso, a norma padrão de escrita, muito mais próxima do dialeto das classes dominantes, considerada por esse modelo o único correto, acirrou a discriminação dos setores mais pobres. A desvalorização e a grande dificuldade encontrada por essas classes neste processo escolar acabam sendo fatores que contribuem para o chamado fracasso escolar, caracterizado pelos altos índices de repetência e abandono escolar.

A mudança ocorrida nos últimos anos em relação à concepção de indivíduo alfabetizado é outro fator, além do fracasso escolar, que determinou mudanças no processo de alfabetização escolar tradicional. SOARES (1995) escreve sobre um novo conceito de alfabetização que vem se impondo pela atual realidade social, pois “(...) dos indivíduos já se requer não apenas que dominem a tecnologia do ler e do escrever, mas também que saibam fazer uso dela, incorporando-a a seu viver, transformando assim seu 'estado' ou 'condição', como conseqüência do domínio desta tecnologia” (p. 7). Surge, segundo a autora, um novo termo - "o alfabetismo ${ }^{2}$, designando o 'estado' ou

\footnotetext{
${ }^{2}$ Em publicação recente, SOARES (1998) passa a utilizar o termo Letramento como sinônimo de Alfabetismo.
} 
'condição' que assume aquele que aprende a ler e escrever" (id. p.6) - um conceito complexo que engloba, além de um conjunto de comportamentos individuais, como as habilidades técnicas de leitura e escrita, um conjunto de atividades sociais. Segundo a autora, ler e escrever são, de um lado, processos que envolvem o relacionamento entre símbolos escritos e unidades sonoras; mas, por outro, também são processos de construção de interpretação de textos escritos (leitura) e de expressão de idéias e de organização de pensamento (escrita). Assim, as habilidades técnicas, que compõem a dimensão individual do alfabetismo, relacionam-se com as práticas sociais associadas à leitura e à escrita. Em outras palavras, não bastam as habilidades individuais; o alfabetismo ( ou letramento) implica no que as pessoas fazem com tais habilidades, nos diversos contextos.

A escola tradicional considera apenas a dimensão individual do processo. Atualmente, considerando a alfabetização como um fenômeno cultural e socialmente construído, SOARES identifica duas concepções relacionadas com a dimensão social da alfabetização:

- a "progressista-liberal", que se define como um conjunto de habilidades e conhecimentos que instrumentalizam o indivíduo para que possa participar das atividades de leitura e escrita, capacitando-o, para o progresso social e individual, bem como para a promoção da cidadania. Entretanto, SOARES (1995) questiona essa visão da dimensão social do alfabetismo, considerando-a inadequada, pois “(...) este é caracterizado em função das habilidades e dos conhecimentos considerados necessários para que o indivíduo 'funcione' adequadamente em um determinado contexto social (...) seu pressuposto é a crença de que o alfabetismo tem, necessariamente, conseqüencias positivas, e apenas positivas" (p.10-11). O alfabetismo funcional, como é conhecido, por não levar em conta as contradições, o questionamento dos valores, das tradições e dos padrões de poder existentes numa sociedade, funciona apenas como um instrumento de adaptação do sujeito à sociedade. Tal concepção não visa à transformação das relações sociais, mas apenas ao aperfeiçoamento dos indivíduos para que possam corresponder às demandas do social, principalmente do sistema de produção;

- a "radical-revolucionária" vai mais além, pois dá ao alfabetismo um significado políticoideológico, não o interpretando como fenômeno autônomo e neutro, mas relacionando-o dialeticamente a um processo social amplo “(...) o alfabetismo é, nessa perspectiva, um conjunto de práticas governadas pela concepção de 'o que', 'como', 'quando' $e$ 'porque' ensinar ler $e$ escrever” (SOARES, 1995: $\mathrm{p}$. 11). O conceito de alfabetismo (ou letramento) é, então, determinado não universalmente, mas de acordo com os usos que cada sociedade faz das práticas de leitura e escrita. Sua força está em possibilitar, pela conscientização, a transformação das "relações $e$ práticas sociais consideradas indesejáveis ou injustas" (SOARES, 1995: p. 12). Neste 
sentido, FREIRE (cf. citado em FREIRE e MACEDO, 1990) afirma que a alfabetização é um ato político e portanto não pode ser reduzida ao puro aprendizado mecânico de leitura e escrita. Ele acredita que a alfabetização deve ser parte do processo através do qual os homens, além de aprenderem a ler e a escrever, deveriam se responsabilizar pela transformação social. "Ser alfabetizado não é ser livre; é estar presente e ativo na reivindicação da própria voz, da própria história e do próprio futuro" (GIROUX, cf. citado em FREIRE e MACEDO, 1990: p.11).

Assim, nesta perspectiva, a conscientização passa a ser o conceito central tanto da teoria quanto do processo pedagógico daí derivado. Segundo FREIRE (1980), ela deveria ser "o primeiro objetivo da educação” (p. 40). FREIRE a define "como ação cultural para a liberdade, (...) processo mediante o qual se adquire, na relação sujeitoobjeto, a capacidade de captar a unidade dialética entre o eu e o objeto" (FREIRE, cf. citado por TORRES, 1979: p. 80), sendo este objeto a realidade vivida. Tal processo se dá pela auto-inserção crítica na realidade, através da desmitologização da mesma.

FREIRE salienta que a conscientização como processo passa por etapas a partir da consciência ingênua, em direção à consciência crítica. Tal passagem, segundo o autor, "somente se dá com um processo educativo de conscientização" (FREIRE, 1979: p. 39), não acontecendo aleatoriamente.
A consciência ingênua é caracterizada por FREIRE (1979) por sua simplicidade na interpretação dos problemas, acarretando conclusões superficiais e explicações mágicas. Subestima o homem simples e considera o passado sempre melhor. Interpreta a realidade como estática e imutável recusando, portanto, a possibilidade de qualquer mudança. É dirigida pela emoção e acredita conhecer tudo. É incapaz para o diálogo, fundamenta-se apenas na polêmica. Por sua vez, a "consciência crítica" caracteriza-se pela profunda análise dos problemas, reconhecendo sua limitação quanto aos meios para resolvê-los. Reconhece a realidade como mutável, é receptiva ao novo e ao velho na medida em que os considera válidos. Explica os problemas através dos princípios causais e não por explicações míticas. Faz o possível para livrar-se dos preconceitos. É inquieta, indagadora, ama o diálogo e nutre-se dele. É racional, verifica e testa as descobertas disposta a revisá-las.

Assim, se a educação crítica pretende proporcionar o amadurecimento da consciência, não pode perder de vista o conflito, as diferenças, as contradições e o questionamento sobre a realidade. É esta reflexão crítica, feita com base no diálogo e nas trocas, que levará os educandos a superarem as ideologias, a perceberem o caráter histórico e mutável das relações sociais e, portanto, reconhecerem-se como sujeitos na construção de si mesmos e da realidade que, por não ser estática, está sempre em evolução.

O diálogo e o questionamento têm importante papel no que FREIRE definiu como Pedagogia da Pergunta, que pressupõe uma postura problematizadora 
sobre a dialetização homem-mundo. A proposta que defende "estimular a certeza de nunca estar certo o bastante" (FREIRE, 1990: p. 39) e de não aceitar o que foi dito sem antes questionar, tem por objetivo levar o aluno " a compreender que a dimensão mais profunda de sua liberdade encontra-se precisamente no reconhecimento das coerções que podem ser superadas. Então, descobrem, no processo de se tornarem cada vez mais críticos, que é impossível negar o poder constitutivo de sua consciência na prática social de que participam” (id. p. 31).

O papel da alfabetização neste processo, que tem por base uma pedagogia emancipadora, visando à formação do cidadão crítico, é o que será discutido neste trabalho. Porém, vale lembrar, como cita Macedo, que "para que a alfabetização ganhe significado, deve ser situada dentro de uma teoria de produção cultural e encarada como parte integrante do modo pelo qual as pessoas produzem, transformam e reproduzem significados" (FREIRE e MACEDO, 1990: p. 38). Da mesma forma, que ela se caracteriza no interior de um projeto político que deve afirmar o direito a cada educando de dizer sua própria voz. Assim, não se pode esquecer que, como alertam os autores, “(...) a alfabetização pode e tem sido empregada para o controle social e para a repressão política também” (GRAFF, 1991: p. 91); “(...) o alfabetismo pode ser um instrumento tanto para libertação quanto para a domesticação do homem, dependendo do contexto ideológico em que ocorre" (SOARES, 1995: p. 12); "(...) nem a escrita, nem a imprensa sozinhas são um 'agente de mudança'; seus efeitos são determinados pela maneira pela qual a agência humana as explora num contexto específico" (GRAFF, 1991: p. 33).

Paulo FREIRE desenvolveu seu projeto pedagógico visando à emancipação do homem, tendo planejado o processo de alfabetização como um importante instrumento de conscientização. Seu projeto, porém, foi dirigido à educação de adultos mas, com certeza, é uma proposta inspiradora de muitas reflexões. Não seria possível alfabetizar crianças segundo o mesmo referencial teórico? Ajudá-las, desde cedo, a desenvolver a consciência crítica e assim a se reconhecerem como sujeitos?

Crianças não são iguais aos adultos. Têm várias diferenças e a organização da estrutura cognitiva é uma delas. Porém, assumindo-se, como FREIRE, a conscientização como primeiro objetivo de uma educação crítica, pode-se também pensar a educação infantil nesta perspectiva. Conscientizar é um processo relacionado diretamente à realidade que independe da idade. Na verdade, é um processo cuja gênese pode estar situada no início da escolarização e ser desenvolvida durante todo este período. A especificidade, neste caso, está no fato de que esta é uma realidade vivida por crianças e será pensada também por elas. Porém, qualquer que seja o aspecto da realidade a ser tratado, não se pode perder de vista a idéia da ação-reflexão, mesmo em se tratando de crianças, como um dos eixos centrais norteadores do processo.

Vale também lembrar que Paulo FREIRE nunca pretendeu escrever um manual de suas idéias. Coerente com sua teoria de que cada um constrói seu conhecimento a partir da elaboração do que é ouvido e vivido, deixou registrado que pretendia 
desafiar os educadores a tomarem sua prática como objeto de reflexão pessoal e a analisarem seu próprio contexto de modo a poder reinventá-la.

A presente pesquisa foi inspirada nessas idéias. Tem como objetivo caracterizar o processo de alfabetização escolar numa perspectiva crítica, a partir de relatos verbais de educadores reconhecidamente envolvidos com a questão.

\section{MÉTODO - \\ DESCRIÇÃO DOS SUJEITOS PARTICIPANTES E DO PROCEDIMENTO DE ESCOLHA}

Partindo-se do pressuposto de que as fontes mais apropriadas para a indicação das características de um processo de alfabetização escolar crítica seriam profissionais que, de uma maneira ou outra, tivessem reconhecido envolvimento com o assunto, optou-se pela escolha intencional, formada por poucos sujeitos. Os critérios definidos para esta seleção foram os seguintes:

a) sujeitos que tivessem assumido uma concepção de alfabetização escolar considerada moderna, tendo superado a visão tradicional, mecanicista, centrada na cartilha, em que a escrita é assumida apenas como representação da linguagem oral;

b) que tivessem demonstrado uma postura teórica receptiva em relação às idéias de Paulo FREIRE, mesmo que ainda não as tivessem considerado em relação à alfabetização de crianças.

Quatro sujeitos foram selecionados a partir de indicações feitas por profissionais universitários. Após um contato telefônico inicial, realizaram-se entrevistas com os indicados a partir das quais decidiu-se pelo grupo final, de acordo com os dois critérios estabelecidos.

Os participantes tinham idades variando entre 30 e 50 anos. Três eram do sexo feminino e um do masculino. Todos tinham ou tiveram envolvimento direto com salas de alfabetização e mantinhamse atualizados com a literatura da área. Segue-se uma breve caracterização dos sujeitos.

Um dos entrevistados -S1- era professor formado em curso de Pedagogia. Atuou durante quatro anos como professor das séries iniciais. Deu assessoria a professores de primeira a quarta séries na área de ensino de língua portuguesa. Fez mestrado e estava concluindo doutorado na área de Linguística Aplicada. Atuava, também, como professor de Prática de Ensino para alunos de Pedagogia. Outro participante -S2- era professor formado pelo Curso de Formação para o Magistério. Trabalhou durante nove anos com salas de primeira a quarta série. Mais tarde formou-se em Letras. Foi supervisor de escola. Fez mestrado na área da Lingüística. Cursou o doutorado nos Estados Unidos, trabalhando com a questão da linguagem oral. Na época, trabalhava no Departamento de Lingüística de uma universidade, onde pesquisava a questão da Língua Materna, especificamente com a fase inicial do processo de aquisição da escrita. $\mathrm{O}$ terceiro entrevistado -S3- trabalhou durante quinze anos como alfabetizador num processo de educação tradicional. Sentindo-se motivado por suas reflexões sobre o fracasso de alguns alunos, procurou novas concepções de educação que ajudassem a responder suas angústias. Trabalhou durante por treze anos com o 
construtivismo "pós-piagetiano", como faz questão de enfatizar. Um novo desafio o mantinha em constante pesquisas, pois na época dava aulas para crianças com Sídrome de Down. O último participante S4- deu aulas durante os três primeiros anos de formado, em classes do ciclo básico, usando a cartilha por imposição da coordenação da instituição onde trabalhava. Após este período, conseguindo superar os obstáculos, desenvolveu um trabalho bem diferenciado, o qual serviu como base para sua dissertação de mestrado. $\mathrm{Na}$ época da coleta de dados dava aulas em curso de Habilitação para o Magistério.

\section{PROCEDIMENTO DE COLETA E ANÁLISE PRELIMINAR DOS DADOS}

O procedimento de coleta de dados usado nesta pesquisa foi $o$ de entrevistas recorrentes, escolhido com base nos trabalhos desenvolvidos por ZANELLI (1992), GUANAIS (1995) e ESTEVAM (1995). Tal procedimento teve suas origens nos trabalhos de BORI (1978), TUNES (1981), SIMÃO (1982) e GOYOS (1986).

Este procedimento caracteriza-se por uma série de entrevistas individuais com o objetivo de esgotar as opiniões do sujeito com relação ao tema introduzido na primeira entrevista, através de uma questão aberta. Após esta primeira entrevista, os dados são analisados e reapresentados ao sujeito, que tem a oportunidade de ampliá-los, alterá-los, suprimi-los, etc. O mesmo ocorre com relação aos relatos verbais coletados na segunda entrevista. Segue-se uma descrição mais detalhada do procedimento.
A primeira entrevista foi marcada através de contato telefônico com cada sujeito selecionado. Neste encontro, após novos esclarecimentos sobre o objetivo da pesquisa e sobre o procedimento de coleta de dados adotado, foi apresentada a seguinte questão: $E$ comum, entre os educadores, a posição de que a escola poderia ter como objetivo o desenvolvimento de cidadãos críticos. $\mathrm{Na}$ sua opinião: a) o que caracterizaria o cidadão crítico?; b) como o processo de alfabetização escolar poderia colaborar com a formação do cidadão crítico?

A pergunta foi apresentada oralmente e por escrito para que o entrevistado pudesse recorrer a ela sempre que preciso. Em seguida, solicitou-se ao participante que falasse livremente sobre o tema. Não havia intervenção por parte do pesquisador.

Esta primeira entrevista durou em média uma hora. Cabe colocar que, antes de entregar a pergunta, foi pedido que cada participante falasse sobre sua formação profissional. Todas as verbalizações foram inteiramente gravadas e posteriormente transcritas.

Depois da primeira entrevista, foi feita uma análise para selecionar os relatos verbais que mais diretamente se relacionavam com o objetivo da pesquisa. Esses relatos, após numerados, compuseram um quadro escrito, que se chamou matriz. Segundo ZANELLI (1992), essa matriz tem a função de "facilitar visualmente ao participante a percepção dos conteúdos que ele próprio fornece, na tentativa de responder a questão inicial, conforme interpretadas pelo pesquisador” (p. 58). 
Assim, cada matriz era composta por colunas onde aparecia, na parte superior, um título indicando o tema tratado em cada uma delas. Estes temas dividiam-se em categorias e sub-categorias nomeadas, formadas pelos conteúdos verbais devidamente transcritos. Nas diversas classes foram transcritos, na íntegra, trechos da fala do entrevistado para exemplificar a análise feita pelo pesquisador. Além disso, havia também na matriz uma coluna denominada "dúvidas", onde eram escritas as questões que o pesquisador solicitava que fossem aprofundadas pelo entrevistado na próxima entrevista.

Num segundo encontro, o participante recebia: a) um quadro contendo todos os relatos verbais emitidos pelo sujeito, devidamente numerados e, b) a primeira versão da matriz para que o sujeito examinasse a classificação dos relatos transcritos, acrescentando, completando ou alterando a análise feita pelo pesquisador. Esta nova sessão também foi gravada e transcrita. As novas verbalizações selecionadas foram numeradas e colocadas em seqüência às anteriores no quadro. Estas últimas serviram como base para a reestruturação da matriz. Assim, num terceiro encontro, a segunda versão da matriz e o quadro ampliado eram entregues ao entrevistado para que este procedesse da mesma forma que na sessão anterior.

O procedimento era repetido até que entrevistado e pesquisador estivessem satisfeitos com as respostas dadas. $\mathrm{Na}$ presente pesquisa, foram realizadas três entrevistas com cada sujeito.

\section{ANÁLISE E INTERPRETAÇÃO FINAL DOS DADOS}

Esta fase caracteriza-se, segundo ZANELLI (1992), por um "procedimento de sistematização de conteúdos verbais em conjuntos temáticos" (p. 69) realizado agora somente pelo pesquisador.

Tendo em mãos os relatos analisados e organizados nos quadros e nas matrizes, o pesquisador comparou-os, identificando os grandes temas abordados pelos sujeitos. Esses temas foram chamados de conjuntos temáticos.

Essa análise final deu origem a quatro conjuntos temáticos:

a) definição de cidadão crítico;

b) a escola e sua relação com o processo de formação do cidadão crítico;

c) crítica às práticas tradicionais;

d) o processo de alfabetização numa perspectiva crítica.

Cada conjunto temático contém categorias e sub-categorias de análise que englobam os diferentes relatos verbais dos participantes, relacionados com o objeto da pesquisa, no caso, os aspectos teórico-metodológicos considerados integrantes de um processo de alfabetização escolar crítico.

\section{DESCRIÇÃO DOS RESULTADOS}

O Quadro 1 apresenta os quatro conjuntos temáticos, com suas respectivas categorias e sub-categorias, resultantes da análise final.

Em seguida, apresentam-se as descrições de cada uma delas, com exemplos de relatos verbais emitidos pelos sujeitos, cuja identificação segue entre parênteses. 


\section{QUADRO 1}

\section{Conjuntos temáticos com respectivas categorias e sub-categorias}

\section{O CIDADÃO CRÍTICO}

1.1. O cidadão crítico como um sujeito historicamente situado

1.1.1. A reflexão e o questionamento como fundamentos para a

1.1.2. A relação ação-reflexão constituindo o cidadão crítico

\section{A ESCOLA E O CIDADÃO CRÍTICO}

2.1. A escola como um recorte da realidade

2.2. O papel da escola no desenvolvimento da consciência crítica

2.3. O professor e sua participação na formação do cidadão crítico

\section{A CRÍTICA ÀS PRÁTICAS TRADICIONAIS}

3.1. Os mitos criados pela prática tradicional e suas conseqüências

3.1.1. A norma culta como a única correta

3.1.2. O uso do pseudo-texto na sala de aula

3.1.3. O professor visto como "babá"

3.1.4. Escrever é um castigo

3.2. As relações autoritárias e a escola tradicional

\section{O PROCESSO DE ALFABETIZAÇÃO NUMA PERSPECTIVA CRÍTICA}

4.1. Os princípios teóricos da alfabetização crítica

4.1.1. A alfabetização como parte do processo de formação do

4.1.2. O professor crítico como mediador no processo de

4.1.3. O aluno como sujeito no seu processo de conhecimento

4.1.4. A concepção de leitura e escrita norteadora deste processo

4.1.5. A variedade lingüística e suas implicações

4.2. Os princípios pedagógicos e as práticas deles derivadas

4.2.1. O uso da linguagem escrita em sala de aula

4.2.1.1. A leitura e a escrita como possibilitadoras de

4.2.1.2. A informação veiculada pela escrita

4.2.1.3. O registro de fatos como auxiliar na compreensão

4.2.1.4. A escrita como forma de se fazer conhecer

4.2.2. A produção e a leitura de textos numa perspectiva crítica

4.2.2.1. A importância dos temas para as atividades de

4.2.2.2. A leitura e releitura, práticas que precisam ser

4.2.2.3. A correção coletiva e o respeito à autoria

4.2.3. O trabalho em grupo como possibilitador da formação crítica

4.3 As dificuldades encontradas num enfoque inovador de alfabetização 


\section{O CIDADÃO CRÍTICO}

Este conjunto temático é composto por uma única categoria, onde se encontram as verbalizações dos participantes que se referem à tentativa de definição do cidadão crítico, indispensável na caracterização de um processo de alfabetização que visa justamente colaborar com sua formação.

\subsection{O cidadão crítico como um sujeito historicamente situado}

Nesta categoria incluem-se os relatos que caracterizam o cidadão crítico a partir da inter-relação do sujeito e da realidade a que pertence.

\subsubsection{A reflexão e o questionamento} como fundamentos para a consciência crítica

Esta sub-categoria apresenta os conteúdos verbais que se referem ao cidadão crítico como um sujeito que tenha desenvolvido a consciência crítica.

A reflexão sobre a realidade vivida na tentativa de conseguir transpor os obstáculos que dificultam o seu reconhecimento foi um dos principais pontos discutidos pelos participantes. Assim, o cidadão crítico foi apontado como sendo um sujeito que:

a. tenha desenvolvido a capacidade de perceber a realidade como ela é, reconhecendo seus conflitos e suas contradições baseadas nas relações de poder que nela se instalam. A seguir um trecho da fala de um dos entrevistados que completa esta idéia:

“... (cidadão crítico) é aquele que reflete sobre aquilo que está vivendo, que está experimentando, não é simplesmente aquele que repete o que lhe foi dito" (S2);

b. reconheça a realidade como mutável, percebendo a totalidade e a temporalidade dos fatos para que, assim, seja capaz de "construir, ainda que utopicamente, a possibilidade de novas relações" (S1);

c. seja questionador, não aceite o que lhe é dito sem antes refletir sobre, pois , como concluiu outro participante, o " (cidadão crítico) é aquele que pensa, que é capaz de minimamente ter sua opinião ...” (S3);

d. perceba que sua consciência é "formada no social, nas relações sociais, nas limitações e nas possibilidades" (S4) e que, portanto, deve estar sempre questionando até suas próprias convicções;

e. seja capaz de se compreender dentro da realidade, reconhecendo inclusive os "limites de sua atuação" (S4,26);

\subsubsection{A relação ação-reflexão constituindo o cidadão crítico}

As verbalizações dos participantes sobre o cidadão crítico como um sujeito atuante estão relacionadas diretamente às que dizem respeito ao sujeito reflexivo, pois, para uma ação efetiva, torna-se necessário o reconhecimento da realidade através do questionamento das relações que a compõem. A divisão feita aqui serve 
apenas para uma análise mais aprofundada destas características que dialogam na composição do cidadão crítico.

Um sujeito atuante caracteriza-se, então, como alguém que seja capaz de se colocar, que "não corra se alguém bater o pé na frente dele e que saiba fazer valer seus direitos" (S3); para isso "é fundamental que ele seja o autor de suas escolhas" (S4), que questione as situações com que não concorda, revindicando mudanças como na situação descrita por um dos participantes: "Os meus alunos (...) eram tidos como muito políticos demais (...) Políticos no sentido de se queixar das coisas” (S4).

Neste mesmo sentido, outro entrevistado exemplifica: “ (o cidadão crítico) não é aquele, por exemplo, que simplesmente pertence a um partido político de esquerda, é aquele que questiona o próprio partido político a que pertence" (S2).

O mesmo participante conclui que o cidadão crítico forma-se na reelaboração do real, “... não é o acúmulo de coisas que vai dar o cidadão crítico, é o questionamento e a reelaboração que vai formar este cidadão crítico” (S2).

\section{A ESCOLA E O CIDADÃO CRÍTICO}

Fazem parte deste conjunto temático as verbalizações que discutem a influência da escola na formação do cidadão crítico. Considera-se a escola como um ambiente onde o processo de ensino-aprendizagem é conduzido intencionalmente.
Este conjunto temático foi dividido em três categorias.

\subsection{A escola como um recorte da realidade}

Incluem-se aqui as verbalizações que caracterizam a escola como um espaço que, por fazer parte da sociedade, traz em si as relações que constituem a própria sociedade. A citação de um dos participantes esclarece esta idéia: "eu acho que a escola tem condições, porque é um espaço muito cheio de conflitos, de formar cidadãos que são capazes de compreender o porque deste conflito" (S1). E, continua, “(...) uma escola inserida numa sociedade de classes, cheia de conflitos, com contradições cotidianas, que acabam permeando a própria continuidade da escola” (S1).

Esse conflito é gerado pelas contradições entre as relações de poder, as diferentes manifestações culturais e sociais, as variedades lingüísticas, que são amplamente encontradas neste ambiente rico em relações que é a escola.

\section{2. o papel da escola no desenvolvimento da consciência crítica}

Esta categoria refere-se aos conteúdos verbais que discutem a função da escola no processo de conscientização dos alunos através da sua ação para a desmistificação da realidade.

"A escola só poderá formar o cidadão crítico se respeitar as diferenças que se encontram dentro dela (...) não é desfazendo das diferenças ou marcando 
as crianças como melhores ou piores, mais corretas, mais erradas que vai conseguir formar o cidadão crítico" (S2).

Assim, a escola deve, através do questionamento e da reflexão, levar seus alunos a desfazerem preconceitos linguíísticos, sociais e culturais.

Um dos participantes coloca, ainda, que a escola deve ensinar seus alunos "que eles vão viver na sociedade e não na escola onde eles estão protegidinhos ..." (S3). Defende, assim, que a escola não deve ter uma função paternalista, necessitando assumir o objetivo de desenvolver a autonomia de seus alunos.

Neste sentido, um outro entrevistado declara que: “... é preciso trabalhar com a questão da argumentação (...) Isso a escola nunca trabalha, ela coloca a criança num mundo infantilizado. Talvez, o máximo que passa são máximas de moral (...) e não leva a criança em nenhum momento a exercitar este uso da linguagem, que é um uso importante para a vida dela fora da escola como um cidadão atuante na sociedade em que ela viva” (S2). A argumentação envolve conhecimentos de linguagem como: organizar, hierarquizar e contrapor argumentos e, portanto, precisa ser desenvolvida na escola.

\subsection{O professor e sua participação na formação do cidadão crítico}

Nesta categoria encontram-se os conteúdos verbais que valorizam a figura do professor num processo educativo diferenciado. Todos os participantes colocaram que só um professor que atue como um cidadão crítico poderá possibilitar o desenvolvimento da postura crítica de seus alunos, pois como lembra um dos entrevistados: "Eu vejo a conscientização meio que uma conseqüencia mesmo do tipo de trabalho que a gente faz. Não acredito muito que você tem que se conscientizar para depois desenvolver um trabalho" (S4).

Este processo dependerá, então, de "um cidadão crítico professor" (S1) que esteja constantemente avaliando e refletindo sobre suas ações tanto como profissional como cidadão, sendo necessário para isso que seja um pesquisador dos conhecimentos elaborados pelo homem; um professor que atue como mediador entre a criança e esses conhecimentos; que baseie sua atuação em sala no respeito às diferenças intelectuais, linguiísticas, culturais e sociais de seus alunos; que valorize o questionamento e o diálogo na intenção de esclarecer a realidade vivida e a interação e a troca como base para a construção de novos conhecimentos.

A citação de um dos entrevistado reforça a importância de que o professor seja reflexivo, pois "a reflexão do próprio trabalho, buscando referenciais teóricos para pensar seu próprio trabalho, com isso ele estaria repensando não só ele enquanto professor crítico mas, também, como um professor cidadão crítico $e$ consequentemente atuando na sociedade não mais como um professor mas como um cidadão crítico" (S1).

O professor tem um papel fundamental na formação do cidadão crítico em função do espaço de escolha que delega para seus alunos. Mas é importante também que os leve a refletirem sobre os limites que existem para a condição de escolha; limites criados nas relações sociais: " $E u$ 
escolho dentro de um certo limite. Numa sala de aula, o que é que dá para escolher de fato? Tem limites. Começa do horário, começa das pessoas que se juntam. Quem escolhe isso?” (S4).

Um dos entrevistados lembra que um professor crítico deve preocupar-se principalmente com os que estão tendo dificuldades de aprendizagem, trabalhando de maneira diferenciada com essas crianças até que aprendam. O professor deve saber, como declara o mesmo participante, qual "o parâmetro mínimo, onde eu quero chegar minimamente com todos (os alunos) (...) os que passarem é lucro (...) os que estão para baixo (...) estes que eu tenho que me preocupar” (S3).

Dois dos participantes abordam a questão da autoridade que o professor deve ter sem, contudo, ser autoritário: “ ... por isso que eu falo que não dá para falar tanto em parceria porque o professor ainda é a autoridade. E a hora que é para escrever, por mais que se discuta como, quando, porque mas acaba tendo esta determinação" (S4). "Sempre o professor é a autoridade na sala de aula. Não precisa ser autoritário mas tem que ser autoridade ..." (S3). Assim, além de organizar os diálogos, os conteúdos, o professor deve estar sempre recuperando com os alunos as regras e os objetivos combinados.

O professor deve estar consciente de seu papel na sala de aula para poder ser competente no que faz. "Ser professor não é missão, é uma profissão como outra qualquer" (S3).

\section{A CRÍTICA ÀS PROPOSTAS TRADICIONAIS}

Este conjunto temático foi composto pelas verbalizações dos participantes que apresentam críticas às práticas fundadas em uma concepção tradicional de alfabetização e da própria relação professor-aluno.

\section{1. os mitos criados pela prática educativa tradicional e suas conseqüências}

Nesta categoria estão situadas as falas dos entrevistados referentes à super valorização da norma culta, do saber pronto e acabado e do papel do professor tradicional. Referem-se, ainda, às ações que acabam impossibilitando a formação de um sujeito com as características descritas no primeiro conjunto temático: cidadão crítico.

\subsubsection{A norma culta como a única correta}

A super valorização da norma culta acarreta a discriminação dos alunos devido às suas diferentes manifestações lingüísticas. $\mathrm{Na}$ escrita, afasta o texto das situações de interlocução e acaba passando a idéia da linguagem escrita "como um conhecimento construído, que está na gramática, que está no dicionário e fazendo a criança decorar aquilo" (S2).

Esta maneira acrítica de tratar o ensino da linguagem escrita "vai acabar produzindo, no final, pessoas que saem da escola falando que 'eu não sei português' e 'eu não gosto de português' como se não fossem já falantes de português desde pequenininhos, muito antes de entrarem na escola” (S2). 


\subsubsection{O uso do pseudo-texto em sala de aula}

Pseudo-textos são definidos por um dos participantes como "estes textos fabricados (...), com uma finalidade (escolar) (...), construídos artificialmente, quer dizer, uma série de frases com um único objetivo de chamar a atenção da criança para um determinado emprego de uma determinada letra (...) não está dizendo nada a ninguém, (...) não tem textualidade" (S2). A cartilha, tão usada no ensino convencional, é um exemplo disto.

O seu uso acaba servindo de modelo para a escrita da criança acarretando situações como aquelas com que o $\mathrm{S} 1$ se deparou: “(...) os textos tinham uma qualidade muito escolar, (...) não era uma qualidade de texto, (...) os textos eram desprovidos do autor" (S1); além da constatada diminuição na quantidade e na intenção de escrita das crianças no decorrer das séries iniciais.

No depoimento de um dos entrevistados, descrito a seguir, pode-se identificar um outro problema acarretado pela utilização da cartilha como base para o processo de ensino: “(...) nos primeiros quinze anos eu trabalhei num processo bem convencional, usando cartilha (...) muitos destes quinze anos eu usei a mesma cartilha. E, quando o aluno não conseguia aprender, a grande chance que eu lhe dava era repetir tudo igual" (S3).

Deve-se registrar a citação de um dos participantes de que quando um texto verdadeiro é trazido para sala de aula, ele "só serve para recortar" (S4). O que, segundo ele, deturpa o conceito da escrita em materiais como: jornal, revistas, etc.
Não se valoriza a função social destes textos que é a de veicular informações.

\subsubsection{O professor visto como "babá"}

Outro ponto é que existe na escola tradicional a falta de clareza na definição dos papel do professor. Ele é visto pelos pais, muitas vezes, como um missionário e não como um profissional. Um dos entrevistados declara sua frustração: " $E u$ era uma babá mesmo. Eu não conseguia passar uma postura profissional nem para o pai do meu aluno" (S3).

\subsubsection{Escrever é um castigo!}

Um dos participantes refere-se à postura de um professor tradicional que, quando alguma criança faz algo de errado, muitas vezes lhe é pedido que faça uma cópia. $\mathrm{E}$ acrescenta: "O pior disto é a conotação de castigo que se dá para escrita! E depois dizem que os alunos não gostam de escrever" (S3).

\subsection{As relações autoritárias e a escola tradicional}

Um dos entrevistados citou que "o que é mais forte na crítica (...) que aponta um ponto central, seriam as relações entre os sujeitos, uma relação muito hierarquisada, (...) muito forte que não dá ao sujeito possibilidade de produção, produção de leitura e escrita" (S1). Ele referia-se tanto às relações autoritárias entre a direção e os professores como à relação entre o professor e seus alunos, onde aquele é visto como o único que sabe e deve passar os conhecimentos.

\section{O PROCESSO DE ALFABETIZAÇÃO NUMA PERSPECTIVA CRÍTICA}


Deste conjunto temático fazem parte as verbalizações dos participantes referentes aos aspectos teórico-metodológicos do processo de alfabetização escolar considerados decorrentes de uma proposta crítica.

Três categorias foram compostas.

\subsection{Os princípios teóricos da alfabetização crítica}

Incluem-se nesta categoria os conteúdos verbais que versam sobre as concepções de alfabetização visando à formação do aluno como sujeito deste processo e da leitura e escrita como formas de expressão da linguagem.

\subsubsection{A alfabetização como parte do processo de formação do cidadão crítico}

O processo de alfabetização poderá, dependendo da concepção do professor, levar à conscientização dos alunos ou poderá "direcioná-los para um assujeitamento" (S4), categorizando-se assim como "um processo extremamente, profundamente político" (S4), pois o professor deverá ter claro para si o tipo de cidadão que pretende formar.

A alfabetização deve ser vista como um "espaço de interação e de troca” (S1). Um processo a ser construído pela criança e não algo pronto que deve ser apenas transmitido, como confirma a citação: "A alfabetização que formaria este cidadão crítico (...) seria levar esta criança a construir a sua representação da linguagem escrita" (S2).

As crianças "se percebem sujeitos pela prática da escrita” (S4). Uma prática fudamentada na escolha do que escrever, no respeito à autoria de quem escreve $\mathrm{e}$ no conhecimento do porque e para que escrever. Assim, como conclui este entrevistado: "eu vejo a conscientização meio que uma consequência mesmo do tipo de trabalho que a gente faz" (S4).

É importante reconhecer também que "esse processo de alfabetização não vai começar só na escola. Para alguns ele começa muito antes, para outros, que não têm contato com a escrita, pelo menos algum conhecimento trazem, nem que seja sobre o poder que a escrita tem" (S2). ( Obs: a questão do poder da escrita será discutido no item 4.1.3.)

Um dos entrevistados demonstrou, ainda, uma preocupação que deve ser ressaltada: "eu acho que em alfabetização, a única estatística que vale é aquela que não exclui ninguém. Porque todos têm o direito de aprender (...)” (S3).

\subsubsection{O professor crítico como mediador no processo de alfabetização}

Retomando a idéia da necessidade de um professor crítico para um processo de ensino-aprendizagem diferenciado, os entrevistados discutem a função deste professor em relação a um processo de alfabetização crítica.

"O papel do professor seria levar a criança a refletir sobre a escrita, sobre o uso da escrita, sobre o poder da escrita, quer dizer suscitar coisas para ela e com ela. Não é chegar com idéias prontas e transmitir para a criança (...) teria que questionar isso em conjunto com as crianças" (S2). 
É preciso, também, respeitar o que as crianças já trazem para a escola: sua cultura, como um ponto de partida para o processo de ensino-aprendizagem; portanto, para um processo de alfabetização, o professor deverá começar seu trabalho a partir de, como cita um dos entrevistados, "uma avaliação (...) não para classificar a criança mas para saber de onde eu vou partir com o trabalho (...) eu tenho que avaliar o que a criança pensa a respeito da escrita, até onde ela já sabe” (S3).

Este professor tem que estar atento para interpretar os erros da criança como a representação momentânea do conhecimento que está tentando elaborar. Assim, como relata um dos entrevistados, "(um professor crítico) tentaria se perguntar: mas porque isso está acontecendo? $O$ que isso me mostra a respeito de como esta criança está representando, elaborando a escrita?" (S2).

A escrita como forma de expressão da linguagem tem que ser trabalhada em situações reais de interlocução; assim, um dos participantes cita qual deve ser a postura de um professor crítico frente a seu aluno: "eu tenho que considerar o meu interlocutor como inteligente, como sabendo das coisas que eu não sei" (S2). E continua: "Se o professor não considera o aluno como seu interlocutor, se ele fica fazendo só perguntas que ele já sabe a resposta, e o aluno só pode dar as respostas que o professor considera certas, isso aí não é uma situação real de uso de linguagem (...)" (S2).

\subsubsection{O aluno como sujeito no seu processo de conhecimento}

Num processo de alfabetização crítica é necessário que se estabeleça uma relação de confiança, onde o respeito pelo que a criança sabe e é é indispensável para que ela perceba a escrita como mais um instrumento de participação social e desenvolvimento pessoal.

O professor deve reconhecer seu aluno "como capaz, com inteligência e que é capaz de refletir e não simplesmente como alguém vazio" (S2). Deve conhecer e respeitar as diferentes características sócio-culturais das crianças. A variedade linguística foi apontada como uma destas características e será analisada numa categoria especial por ser muito complexa.

Os alunos precisam ter espaço para mostrarem-se sujeitos, "espaço para trazer alguma coisa (conhecimento) para trocar, para que eles pudessem ensinar alguma coisa para o grupo" (S4). Espaço para contarem suas histórias, compartilharem com os outros suas vivências; isto é uma forma de valorização da criança como sujeito ativo no processo de ensino-aprendizagem. Uma outra citação ilustra esta idéia: "nossa aula é assim; resolvendo problemas, se interando com os outros (...) para resolver problemas, (os alunos) tem que usar a criatividade (...) ao usar a criatividade eles vão se sentir como construtor de seu conhecimento" (S3).

O exercício de escolha pelo aluno deve ser um processo cotidiano que pode ser feito a partir do planejamento das atividades a serem desenvolvidas no dia, na semana, etc. "Desde a primeira semana de aula a gente começava combinando a atividade do dia. (...) Eu tinha atividades preparadas, mas eu 
sempre conversava, mesmo que não se decidisse o que propriamente: 'Mas, então! A que horas a gente pode fazer isso? Qual a gente pode fazer primeiro?", (S4). Da mesma forma, tal exercício pode ser efetivado através da escolha sobre "quando" e o "quê" escrever. Toda esta discussão sobre a necessidade do exercício da escolha pelo aluno não pode deixar de lado a idéia do limite, que foi abordada no item 2.3.

Vale citar as verbalizações de dois dos entrevistados referentes à importância deste espaço de escolha, que o professor deve permitir para a formação do cidadão crítico: "Quando têm espaço, eles se dão soluções e respostas (...)” (S3); “Eles resolvem muito fácil estas coisas quando lhes é permitido opinar" (S4).

\subsubsection{A concepção de leitura e escrita norteadora do processo de alfabetização crítica}

A escrita é uma construção sóciohistórica, é uma construção humana e, portanto, é viva, mantém-se em constante mudança, acompanhando a evolução do homem.

Num trabalho apoiado nesta concepção de escrita, "a criança vai compreendendo que as coisas não se dão prontas, elas se constituem" (S1) e é a partir desta reflexão que se desenvolverão práticas através das quais o aluno se sentirá participante do processo de construção da língua escrita.

O processo de alfabetização não pode estar desvinculado da discussão do que seja ler e escrever no seu sentido mais amplo, como formas de relação inter e intra-pessoal. E é baseado na idéia da leitura e escrita como formas de relação social que um dos entrevistados se refere ao "poder da escrita": "O poder da escrita é percebido pela criança desde muito cedo, pois ela está vendo que quem escreve é mais aceito socialmente, mais valorizado" (S2).

Ressalta, então, a necessidade de se refletir com esta criança que o poder da escrita não é intrínseco a ela, é algo construído historicamente. "Revendo toda a história da linguagem e da escrita, você vai ver como é que esse poder vai se constituindo (...) Começam as diferenciações também, junto à construção deste poder, de que você está certo, você está errado, você pode escrever, você não pode escrever, você não está autorizado ..." (S2).

A história da evolução deste poder bem como a da evolução da escrita devem ser conhecida pelas crianças.

\subsubsection{A variedade linguiística e suas implicações}

Quando se fala no respeito aos alunos fica claro para os entrevistados que "ninguém fala errado, as pessoas falam diferente" (S2). E esta variedade lingüística reflete as características culturais do grupo social ao qual o seu falante pertence. $\mathrm{O}$ preconceito lingüístico que diz que a fala de um determinado grupo é a certa ou errada, discrimina a criança e o grupo com o qual ela se identifica.

Portanto, a questão do certo e do errado precisa ser repensada junto com a criança para que ela se conscientize e questione a segregação pela linguagem. Pois, "nenhuma linguagem é intrinsecamente certa ou errada” (S2); qualquer 
variedade segue regras e e tem uma gramática própria.

Além disso, é importante ressaltar a colocação de um dos entrevistados que diz que "ninguém é falante de uma só variedade lingüística” (S2), elas existem tanto em situações de relação pessoal como em grupos sociais distintos. A variedade lingüística é tanto interna ao indivíduo (as diferentes maneiras de falar dependendo das diferentes situações e dos diferentes interlocutores) como externa a ele (dependendo da faixa etária, do grupo social, da região, ...).

A valorização de uma variedade lingüística, considerada padrão tem relação com a apropriação do poder (econômico ou social) pelo grupo que a usa. E, "é em termos desta visão de padrão que as pessoas dizem que quem fala uma outra variedade que é diferente desta padrão está errada” (S2).

\subsection{Os princípios pedagógicos e as práticas deles derivadas}

Nesta categoria incluem-se os conteúdos verbais relativos às atividades de leitura e escrita consideradas integrantes de uma concepção crítica do processo de alfabetização escolar: atividades que se desenvolvem em situações reais de uso de linguagem, onde a interlocução é a principal condição para que o processo ocorra.

\subsubsection{O uso da linguagem escrita em sala de aula}

Situam-se nesta sub-categoria os relatos verbais dos participantes que dizem respeito às atividades que dão à criança a possibilidade de conhecer as funções sociais da escrita, ou seja, atividades que levem o aluno a compreender o porquê e quando se usa a língua escrita. Atividades que permitam a criança usar e refletir sobre a leitura e escrita, como estas se apresentam na vida real, que lhe permitam apropriar-se da escrita como forma de expressão pessoal.

Os usos que foram indicados pelos entrevistados, através dos exemplos de atividades que deram, serão discutidos nos quatro itens elencados abaixo:

\subsubsection{A leitura e a escrita como possibilitadora de comunicação}

"Eu queria trabalhar com a coisa da vida, trazer a vida para dentro da sala de aula para que a escola fique mais interessante" (S3). Foi o que este entrevistado fez quando, no dia dos namorados, surgiu entre as crianças a conversa sobre quem tinha namorado ou não. O professor, então, questionou os alunos sobre o que estaria contido num bilhete para o namorado. Sugeriu depois que quem tivesse um namorado e quisesse, poderia escrever um bilhete para ele. Como várias crianças não tinham, chegou-se à conclusão que deveriam escrever um bilhete para qualquer ente querido. $\mathrm{E}$ assim foi feito com total envolvimento das crianças.

$\mathrm{O}$ entrevistado alerta que os bilhetes foram entregues ao seu destinatário porque, se não fossem, se o professor os recolhesse, teria tirado o significado e esta função da escrita não seria vivenciada, passaria a ser uma atividade puramente escolar com um objetivo bem diferente.

“ (...) bilhetes, cartas para mim, eu escrevia cartas para elas, nós escrevíamos cartas para outras classes 
(...)” (S1). Um dos conteúdos dessas cartas referia-se ao interesse da classe em pedir autorização para usar uma quadra para fazer um piquenique. $\mathrm{O}$ professor então discutiu com seus alunos que um pedido deste teor e dirigido à direção não poderia ser escrito como um carta comum, deveria ter o formato de um ofício, documento oficial destinado a estes fins. Sugeriu que as crianças pesquisassem o que era e como era um ofício para que pudessem escrevê-lo. Foi também argumentado que o ofício, por ser um documento oficial, deveria usar uma forma de linguagem escrita específica, devendo-se cuidar da ortografia, e assim por diante. O documento foi entregue e a quadra cedida.

A produção de textos espontâneos é algo que deve ser incentivado pois estes, por partirem da intenção de quem escreve, terão sempre significado. Como o exemplo que cita o S1: “(...) pai que foi viajar e a criança quer escrever uma carta (...) ela faz uma, duas, três (...) quantas vezes, porque é significativo para ela” (S1).

\subsubsection{A informação veiculada pela escrita}

"Uma revista, por exemplo, um jornal (...) eu levava de casa, (...) um livro diferente, ou alguma coisa que a criança trouxesse de casa (...)” (S4). Este professor teve sempre o cuidado de mostrar e discutir com a classe o conteúdo de qualquer material escrito trazido de fora pelos alunos, bem como sempre que lia um artigo ou uma notícia em seu cotidiano que achasse que poderia ser de interesse de seus alunos, levava para a sala. Com esta postura pretendia mostrar a seus alunos que "a escrita está fora da sala de aula" (S4) e que ela traz informações.

\subsubsection{O registro de fatos como auxiliar na compreensão destes e como suporte de memória}

“(...) então estava sendo discutida a escrita com uma função imediata ali, que era entender como é que se brinca (...)” (S4). As crianças estavam tendo dificuldades de brincar na hora do recreio. Brigavam e discutiam umas com as outras sem conseguir desenvolver alguma brincadeira. O professor interveio e pediu que entrassem na sala para conversar sobre o que estava acontecendo. Chegouse à conclusão que quem soubesse uma brincadeira iria ensinar. Partiu das crianças também a idéia de escrever na lousa e no caderno uma lista de brincadeiras e de regras para que não as esquecessem.

“(...) registrávamos acontecimentos pessoais em diários pessoais (...)” (S1). A proposta era que as crianças registrassem algo importante que aconteceu no dia anterior. O professor ou outro colega só leria esse registro se fosse convidado a ler pois, o objetivo era que as crianças escrevessem o que quisessem guardar.

As atividades desenvolvidas durante as aulas eram também registradas tanto pelo professor como pelos alunos, individualmente, para que no dia seguinte as anotações fossem retomadas $\mathrm{e}$ servissem de apoio para garantir a sequiência do trabalho.

\subsubsection{A escrita como forma de se fazer conhecer}


"Com o passar do tempo chegamos a discutir a escrita como uma maneira de falar consigo mesmo, quer dizer em outras palavras, a busca do autoconhecimento, da reflexão" (S4). Apenas um dos entrevistados levantou esta possibilidade da escrita que é a de auxiliar no conhecimento de si mesmo. Porém, a escrita, como forma do professor conhecer quem é seu aluno, foi citada por vários dos participantes.

\subsubsection{A produção e a leitura de textos numa perspectiva crítica}

Fazem parte desta sub-categoria as verbalizações dos participantes que indicam a concepção de que a produção escrita é uma forma de expressão pessoal. E que o texto é produto de uma prática discursiva, ou seja, "os textos verdadeiros têm interlocutores, eu estou escrevendo para alguém ou para um interlocutor virtual" (S2).

As crianças "se percebem sujeitos pela prática da escrita” (S4). Uma prática fundamentada na escolha do que escrever, no respeito à autoria de quem escreve $\mathrm{e}$ no conhecimento do porque e para que se escreve.

\subsubsection{A importância dos temas para as atividades de escrita}

"Os temas das redações devem ser sugeridos pelas crianças e eles vão ser aceitos ou não (pelo grupo) a partir da discussão" (S4). Esta postura garante que estes sejam temas com os quais as crianças tenham envolvimento para escrever, como por exemplo: "dia chuvoso na escola (...) era um problema porque a escola não tinha pátio coberto" (S4). Assim, os temas, por serem vivenciados pelos alunos tornam os textos “quase um depoimento" (S4).

"Nem sempre todo mundo escrevia sobre o mesmo tema" (S4). As próprias crianças chegavam a esta conclusão: ou levantando um outro tema para os que não aceitaram o primeiro ou, se o número de dissidentes fosse pequeno, eles poderiam escrever sobre algo que quisessem; mas não poderiam deixar de escrever pois este era o objetivo primeiro que foi levantado pelos próprios alunos: aprender a ler e escrever.

“(...) eu tenho que variar as situações de interlocução, eu tenho que aumentar o leque de interlocutores do meu aluno. Ele não pode estar falando só para mim professor. Ele vai ter que estar falando para outros interlocutores, outros até que ele não conhece, ele vai ter que imaginar" (S2). Com este procedimento o professor poderá proporcionar a seus alunos a possibilidade de elaboração de temas diferenciados e consequentemente produzir diferentes tipos de textos com diferentes funções.

\subsubsection{A leitura e a releitura, práticas que precisam ser desenvolvidas}

"Desde a primeira semana, por uma hora, uma hora e meia, eu punha uma quantidade de livros, livrinhos variados em duas carteiras para que eles pudessem escolher, pegar, devolver, folhear (...) não tinha nada combinado além de uma hora e meia com o livro, manuseio mesmo". (S4). O professor constatou que esta atividade que começou com uma hora, no decorrer do tempo foi necessitando mais horas. A leitura não era vista como um produto a ser avaliado mas como um processo em que a criança se desenvolvia 
das mais diferentes formas: "passando a mão na folha do livro, na textura, na cor (...) lendo um trechinho de cada página, ou só folheando, vendo os desenhos" (S4). A interação e o diálogo entre os colegas também fazia parte desta atividade.

"Como sempre acontecia ou quase sempre acontecia, a criança vinha entregar o texto, lia para mim o que estava escrito ali na mesa" (S4). Essa releitura é uma atividade que deve ser desenvolvida pela criança pois permite que ela mesma faça a reelaboração do que escreveu, incluindo algumas correções de ortografia ou de estrutura do texto. O professor nesta atividade é o ouvinte que poderá, eventualmente, problematizar o desempenho do aluno.

“(...) eu pedia: entregue para algum colega ler e ver se ele tem algum comentário para fazer (...)" (S1). Nesta atividade, a leitura pelo outro e seu questionamento provocam a reelaboração da própria escrita e garantem à criança a percepção de que um texto destina-se realmente a um interlocutor e que portanto deve obedecer a algumas características, pois “(...) um texto é coeso, é coerente, tem um certo grau de informatividade" (S2).

\subsubsection{A correção coletiva e o respeito à autoria}

“(...) quando eu expunha um texto, eu copiava do jeitinho que estava na folha e, é claro que as primeiras vezes o que eles viam eram os erros (...) Aí, eu fui falando que (...) a escrita não é só o erro ortográfico, da palavrinha, como eles falavam, mas é a idéia que você transpõe para o papel de alguma maneira” (S4).
De acordo com S4, é importante que a correção coletiva de um texto só seja feita quando autorizada pelo autor e desde que fique claro, para ele, que só será identificado se assim o desejar. Deve-se respeitar a vontade do aluno se ele não quiser que seu texto seja corrigido coletivamente.

Uma correção coletiva, como mostra a verbalização acima, deve promover em primeiro lugar a reorganização das idéias para depois se discutirem os erros formais. A repontuação geralmente acontece em decorrência desta reorganização.

A questão da autoria precisa ser pensada com os alunos. A discussão das idéias contidas no texto deve visar apenas a uma melhor compreensão do que está sendo dito mas as idéis do autor não podem ser mudadas. Pode-se concordar ou não com o que ele diz. Assim, ao final da correção o autor pode aceitar ou não a nova versão de seu texto.

\subsubsection{O trabalho em grupo como possibilitador da formação crítica}

Nesta sub-categoria encontram-se os conteúdos verbais de um dos participantes que, por fundamentar seu trabalho na idéia de que o conhecimento se produz na interação através do diálogo e da troca de outros conhecimentos, valoriza o trabalho de grupo como a melhor dinâmica para que a construção do conhecimento ocorra: “Eu aprendo também com as diferenças. Por isso, e só por isso justifica-se na minha sala o trabalho em grupo (...) eu não acredito nestas classes tipo cemitério, com um tumba atrás da outra. Ninguém aprende sozinho” (S3). 
A escolha do grupo tem que ser feita pelas crianças porque a afetividade é um importante componente para se garantir a interação, caso contrário as crianças apenas se suportariam. O professor deve determinar o número de participantes para que se garanta a possibilidade de um trabalho em grupo e a disciplina. Primeiramente são eleitos os chefes de grupo a partir da discussão das funções que este deverá assumir, como por exemplo, distribuir o material em seu grupo (folhas, jogos, etc); é o responsável pelo cuidado com este material; deve fazer chegar as informações e as atividades aos componentes de seu grupo que faltarem.

Eleito o chefe, este, conhecendo as obrigações que o cargo lhe impõe, poderá ou não aceitar a posição. Se aceitar, ele escolhe apenas o primeiro componente do grupo e a partir daí não é mais apenas o chefe que escolhe, são todos os integrantes deste grupo, em conjunto, que vão escolhendo os demais. Cada criança escolhida pode ou não aceitar fazer parte do grupo, garantido assim o compromisso com o grupo.

Os grupos devem ter no mínimo dois meses de duração para que se forme o "vínculo de grupo" (S3). Durante este tempo o professor poderá fazer as mudanças que julgar necessárias desde que estas sejam discutidas com os integrantes do grupo.

O entrevistado acredita que esta dinâmica permite a discussão e a reflexão sobre as relações encontradas no social como, por exemplo, a responsabilidade vivenciada na escolha do chefe de grupo: "Pode ser o que sempre falta? (...) Daí eu trabalho a questão da falta"; o respeito, ainda na eleição: "Pode ser aquele autoritário que belisca os outros? Que está sempre batendo? Que não ouve a opinião do outro?”; o saber ouvir: “(...) eu posso saber mas o outro também tem a verdade dele e que às vezes é melhor que a minha"; a autonomia desenvolvida nas situações de escolha como quando se formam os grupos e quando o grupo resolve "em que lugar da classe vai sentar” (S3).

\subsection{As dificuldades encontradas num processo inovador de alfabetização}

São colocadas nesta categoria as verbalizações referentes às dificuldades encontradas para a efetivação deste processo, bem como às vivenciadas durante o processo.

"Em condições escolares você não só obedece à exigência do processo mas você obedece a uma exigência (...) a de relações de poder (...)" (S1). Assim, a maior dificuldade está em romper com as relações de poder que existem na escola e que, de uma forma ou outra, controlam o processo de alfabetização. $\mathrm{O}$ mesmo participante indica uma possível solução para esta dificuldade: "Agora para que isso se estenda (um trabalho diferenciado) é preciso ter um acordo entre todos (os professores), e esse acordo pode se chamar projeto pedagógico da escola, e não é necessariamente aquele que vem imposto" (S1).

Um entrevistado alerta que o professor que assume uma proposta como esta tem que estar consciente dela e preparado para não cair em contradição, pois no decorrer deste processo as crianças "ficam com uma crítica muito mais apurada. Então, 
você como professor é colocado contra a parede por eles. Com certeza! Mas aí? Eu continuo com a minha proposta? Ou não?" (S4).

O tempo é outro aspecto importante para um dos participantes, pois o desenvolvimento da consciência crítica não acontece de um momento para o outro; é um longo processo que tem que ser vivenciado para ser aprendido. "Quando a gente está comentando parece que perde esta dimensão temporal da coisa” (p.4).

\section{DISCUSSÃO DOS RESULTADOS}

Inicialmente, é importante ressaltar que todos os sujeitos entrevistados concordaram com a hipótese formulada pela questão apresentada, a qual sugeria que a escola teria por objetivo colaborar na formação do cidadão crítico. A caracterização do cidadão crítico passou, então, a ser central nas entrevistas. Os participantes referiram-se a este como sendo um sujeito que se constitui numa relação dialética com a realidade vivida, desenvolvendo, a partir daí, o que Paulo FREIRE chamou de consciência crítica.

Neste processo de conscientização, o cidadão crítico, em síntese, é aquele que é capaz de reconhecer a realidade como um processo mutante e histórico do qual faz parte e, principalmente, no qual sua consciência é formada. Lembrando FREIRE, "na medida (...) em que a consciência dos homens está condicionada pela realidade, a conscientização é antes de tudo, um esforço para livrar os homens dos obstáculos que os impedem de ter clara percepção da realidade” (FREIRE: 1980, p. 94). Assim, segundo os entrevistados, a reflexão é uma característica fundamental a ser desenvolvida para a constituição do cidadão crítico e deverá ter como base os conflitos e as contradições da realidade vivida.

É a reflexão que, possibilitando ao sujeito o reconhecimento do caráter temporal dos fatos, bem como a compreensão da totalidade complexa entre eles, dá ao cidadão crítico a possibilidade de ação sobre a realidade. É através do questionamento que, segundo os participantes, o cidadão crítico reelabora o real, construindo a possibilidade de novas relações. A conscientização da idéia da realidade como mutável torna-se, então, imprescindível a qualquer pedagogia crítica pois é ela que viabiliza o papel da ação humana.

O cidadão crítico poderia ser, então, definido como alguém que, tendo desenvolvido a consciência crítica, seja capaz de, através da relação dialética entre a reflexão e a ação, participar ativamente da realidade em que vive. Porém, é importante lembrar que o cidadão crítico além de agir a partir da reflexão, também reflete sobre sua própria ação, reconhecendo os limites desta.

“... mas o passo para a consciência crítica não é (natural). Somente se dá com um processo educativo de conscientização" (FREIRE: 1979, p. 39). Se acreditarmos que a conscientização é um processo a ser ensinado/desenvolvido/incentivado, a escola passa a ter, então, um importante papel na formação do cidadão crítico. Como parte da sociedade, a escola é um espaço marcado por conflitos e contradições ocasionados pelas diferentes manifestações culturais e sociais que nela 
se encontram. Isto possibilita um ambiente propício ao exercício da reflexão no sentido do desvelamento da realidade, através do questionamento dos conflitos gerados pelos preconceitos lingüísticos, socais e culturais, pelas relações de poder, etc.

A escola, segundo os participantes, tem a função de instrumentalizar seus alunos para a vida em sociedade. Assim, a reflexão, a autonomia, o diálogo e a argumentação, características de um cidadão atuante, precisam ser ensinadas/desenvolvidas/incentivadas e, principalmente, exercitadas dentro da escola. Segundo os entrevistados, somente um professor que seja um cidadão crítico será capaz de exercer este papel. Pois, como cita Paulo FREIRE (1990), "quanto mais vivemos criticamente (...) mais internalizamos uma prática educativa radical e crítica e mais descobrimos ser impossível separar o ensinar do aprender. A prática mesma de ensinar implica aprendizagem por parte daqueles a quem se ensina, bem como aprendizagem, ou re-aprendizagem, por parte dos que ensinam" (p. 112). Este professor deverá ser um sujeito reflexivo que esteja constantemente avaliando suas ações e que acredite que o conhecimento e o desenvolvimento se dê no embate dialógico das diferenças; portanto, um professor que valorize o diálogo, concebendo-o necessariamente como uma relação horizontal; para isso, é preciso que reconheça seu aluno como capaz e inteligente. Com esta postura, o professor criará um ambiente de confiança entre ele e os educandos, possibilitando que seus alunos ajam como sujeitos no próprio processo de construção do conhecimento, provocando, consequentemente, as condições para o desenvolvimento da consciência crítica.

O trabalho em grupo, como declara um dos entrevistados, deve ser uma estratégia usada por este professor pois promove o aprofundamento das relações interpessoais e contribui para a reciprocidade. Como aponta VYGOTSKY (1994), é na característica heterogênea dos grupos que os conhecimentos de um contribuem para o desenvolvimento do outro; " $O$ aprendizado humano pressupõe uma natureza social específica e um processo através do qual as crianças penetram na vida intelectual daquelas que as cercam" (p.115). Portanto, é através da interação entre as crianças que ocorrem as trocas, $o$ questionamento, o diálogo e a contraposição das diferentes idéias, condições que fundamentam um processo de alfabetização crítica; além de proporcionar a reflexão sobre as atitudes desenvolvidas nas relações com o outro, nas relações sociais, como por exemplo, a responsabilidade, a autonomia, o respeito, a compreensão, a cooperação, etc. A importância do papel do outro na mediação entre a cultura e o indivíduo poderá ser melhor estudada na obra de VYGOTSKY (1994).

Em síntese, nesta perspectiva, o professor crítico será aquele que reconhece a educação como um processo político e que, portanto, deve estar continuamente refletindo sobre o tipo de sujeitos que pretende formar: se homens livres ou dominados.

Se a ação do professor crítico é dirigida para a libertação do homem, o processo de alfabetização desenvolvido por este sujeito será, segundo GIROUX (cf. citado em FREIRE e MACEDO, 1990), um 
projeto de possibilidades que permite aos alfabetizandos participarem da compreensão e da transformação da sociedade. A alfabetização, nesta concepção, amplia a capacidade dos homens de se relacionarem com o mundo social e faz parte do processo de conscientização.

Uma alfabetização será tanto mais crítica quanto mais seus temas trabalharem com as situações conflitantes do cotidiano vivido. O professor crítico deverá atuar, neste sentido, junto a seus alunos incentivando-os a questionar a realidade, possibilitando espaço para que contem suas histórias, façam suas escolhas, compartilhem com os outros suas vivências. Deve estimulá-los a discorrerem sobre o mundo pois, como cita FREIRE (1990), "os alfabetizandos precisam compreender o mundo, o que implica falar a respeito do mundo" (p. 32). Se para refletir sobre a realidade é preciso contrapor diferentes idéias, o professor precisa estar preparado para atuar como mediador, sendo um constante pesquisador, como indicam os entrevistados, dos conhecimentos construídos pelo homem, tanto em relação aos conteúdos sistematizados como em relação às teorias pedagógicas que fundamentem sua prática.

Ainda citando os entrevistados, num processo de alfabetização crítica torna-se necessário que as crianças reflitam sobre o que é ler e escrever e para que serve ler $e$ escrever, a fim de que percebam a alfabetização como mais uma forma de expressão e ação pessoal. Vale novamente citar GIROUX ao afirmar que "ser alfabetizado não é ser livre; é estar presente $e$ ativo na revindicação da própria voz" (cf. citado em FREIRE:
1990, p. 11). Para isso, é preciso que o professor conheça e respeite as diferentes manifestações culturais de seus alunos, entre elas a variação linguística, e leve-os a refletirem sobre a discriminação social acarretada pelo preconceito linguístico.

Na linguagem escrita, a discussão sobre a sua construção sócio-histórica deve ser um dos pontos principais a ser abordado pelo professor. Partindo de um levantamento de quais as concepções de escrita que os alunos já trazem, o professor deve levá-los a refletirem sobre as funções e os usos sociais da escrita, como algo que se constituiu nas diferentes relações entre os homens. O reconhecimento da escrita como um sistema de convenções construído e utilizado pelos sujeitos a partir de suas necessidades sociais é importante para se refletir sobre a valorização da norma culta. O poder da norma padrão, segundo um dos sujeitos entrevistados, tem relação direta com o poder econômico do grupo social que a utiliza. Os alfabetizandos precisam ter consciência destes fatos para que possam utilizar o dialeto padrão como um instrumento de ação e interação dentro do sistema econômico-social dominante. "Neste sentido, a alfabetização se alicerça numa reflexão crítica sobre o capital cultural dos oprimidos. Ela se torna um veículo pelo qual os oprimidos são equipados com os instrumentos necessários para reapropiar-se de sua história, de sua cultura e de suas práticas lingüísticas" (MACEDO cf. citado em FREIRE e MACEDO, 1990: p. 105).

Retomando o pensamento de FREIRE, de que a reflexão, se realmente reflexão, conduz à prática, torna-se importante a idéia defendida pelos participantes de que 
toda atividade proposta em sala deve necessariamente estar relacionada à realidade. Em relação ao processo de alfabetização, estas atividades devem ser desenvolvidas em situações reais de uso da linguagem, tendo a interlocução como condição para que ocorra. Como cita KLEIN (1996), "É preciso que haja homens utilizando de forma real esta linguagem, para que ela se configure enquanto tal" (p. 100).

A mesma autora confirma a opinião dos entrevistados, de que é necessário que as atividades escolhidas sejam aquelas que levem a criança a conhecer e usar a escrita com as funções sociais que a compõem, quando afirma que "(...) o primeiro conteúdo do processo de alfabetização são, justamente, as funções sociais da escrita, ou seja, é necessário, primeiro, que a criança compreenda por que $e$ quando se usa a língua escrita” (KLEIN, 1996: p. 101). Assim, os alunos deverão conhecer ativamente a utilidade social da escrita como, por exemplo, comunicação com um interlocutor ausente, registro dos conhecimentos adquiridos como suporte da memória e como busca de informações, forma de recreação, forma de auto-conhecimento, forma de dizer sua palavra, etc. Todos estes usos e funções da língua escrita só serão conhecidos através do exercício destas diversas formas de escrita.

Portanto, a produção de textos com função social é o eixo do processo de alfabetização, isto é, de textos que sejam produtos de uma prática discursiva que pressupõe interlocutores que poderão ou não estar ausentes mas que precisam ser reconhecidos pelos alunos como tal. É a variação destes interlocutores que, segundo os participantes, permite à criança produzir diferentes tipos de textos com diferentes funções. Deve ser o professor como mediador que possibilitará questionamentos para que esta variação ocorra.

Outro aspecto importante de um processo crítico de alfabetização está relacionado aos temas desta produção. Estes devem fazer parte do universo das crianças, podendo ser sugeridos por elas ou pelo professor, através de sua observação do cotidiano da sala de aula e da realidade que as cerca. Aqui o professor tem um papel importante de provocar o conflito, através dos conhecimentos que também traz, no sentido de ampliar as relações dos alunos com uma sociedade mais ampla. $\mathrm{O}$ que FREIRE (1985) completa quando diz que “(...) a investigação (temática) se fará tão mais pedagógica quanto mais crítica e tão mais crítica quanto (...) se fixe na compreensão da totalidade. Assim é que, no processo de busca de temática significativa, já deve estar presente a preocupação pela problematização dos próprios temas. Por suas vinculações com os outros. Por seu envolvimento histórico-cultural” (p. 118).

A troca dos textos entre os alunos é uma interessante atividade sugerida pelos participantes, pois provoca reflexão e reelaboração da escrita através do questionamento do outro. Esta reelaboração acontecerá tanto ao nível ortográfico como ao nível de coerência de idéias pois, numa atividade como esta, a criança irá perceber que um texto verdadeiro exige uma estrutura adequada que permita a compreensão, primeira condição para uma real interlocução. Neste contexto, a correção passa a ser uma atividade que visa à reflexão sobre “(...) os aspectos convencionais deste 
intercâmbio e a consciência da atividade regrada que é a linguagem" (FRANCHI, 1988: p. 172) possibilitando, assim, o domínio consciente da convenção.

A questão da autoria deve ser aqui também discutida, pois num processo que reconhece o texto como uma forma de expressão pessoal, a palavra do autor deve ser valorizada. Isto não significa que não deva haver a interferência do professor. Esta é importante, mas o professor deve ter o cuidado de considerar aquele texto com a função de interação autor/leitor e não, como alerta SOARES (1988), como uma forma interlocução artificial, como “(...) 'prestação de contas' do autor a um leitor que nada mais espera senão reconhecer, no texto, esse modelo (modelo escolar); que, em vez de possibilidade de intersubjetividade, é, ao contrário, negação da subjetividade de autor $e$ leitor (...) nega (ao aluno) o direito de usar a escrita para dizer sua própria voz" (p.10 e 11).

Ao se refletir sobre a interferência do professor num processo de ensino/aprendizagem, é fundamental discutir a avaliação. Porém, este aspecto não foi muito aprofundado pelos participantes. Apenas um deles se referiu à avaliação descrevendo-a como um instrumento de coleta de dados que permite ao professor um maior conhecimento de seus alunos. LUCKESI complementa esta idéia quando caracteriza o ato de avaliar como uma função diagnostica que objetiva o avanço e o crescimento do aluno. "Como diagnostica, ela será um momento dialético de 'senso' de estágio em que se está e de sua distância em relação à perspectiva que está colocada como ponto a ser atingido à frente"
(LUCKESI: 1984, p.. 9). Assim, num processo de alfabetização crítica, a avaliação não poderá ter "a função estática de classificar um objeto ou um ser humano histórico num padrão definitivamente determinado" (idem). A avaliação, neste sentido, é um conceito ampliado pois torna-se um momento de reflexão sobre a prática, tanto do professor como do aluno que, necessariamente, implica num retorno à própria prática. A avaliação é um meio e não um fim em si mesma.

Sendo assim, um processo de alfabetização crítica se caracteriza "como prática de um projeto político e de uma prática que ofereça uma linguagem de esperança e de transformação dos que lutam por um futuro melhor" (BERTTOFF cf. citado em FREIRE e MACEDO, 1990: p. 5), desde que seja desenvolvido num espaço que retrata a realidade e por um professor que seja um cidadão crítico, que reflita sobre o conflito. Como alerta FREIRE (1990), “o papel mais importante da pedagogia crítica não é terminar com as tensões (...) é levar os alunos a reconhecer as diversas tensões e habilitá-los a lidar com elas eficientemente. Tentar negar essas tensões acaba por negar o próprio papel da subjetividade. A negação da tensão significa a ilusão de ter superado essas tensões quando, na verdade, elas estão apenas ocultas" (p. 31). O processo de conscientização que a alfabetização crítica possibilita visa justamente ao desvelamento desta realidade a fim de que o aluno sinta-se capaz de, através da reflexão e da ação, participar na mudança das relações que julgue necessária. Vale lembrar que o processo de alfabetização crítica faz parte de uma concepção de 
pedagogia que vê a educação como um mecanismo de transformação social. 


\section{REFERÊNCIAS BIBLIOGRÁFICAS}

BORI, C. M. et al. Desempenho de professores universitários no levantamento e caracterização de problemas de ensino : Descrição de um procedimento. In: REUNIÃO ANUAL DE PSICOLOGIA DA SOCIEDADE DE PSICOLOGIA, 8., 1978, Ribeirão Preto. [Anais...] Ribeirão Preto : [s.n.], 1978.

COOK-GUMPERZ, J. Construção social da alfabetização. Porto Alegre: Artes Médicas, 1991.

ESTEVAM, P. L. Um estudo sobre as contribuições da psicologia educacional para a formação dos professores das séries iniciais. Campinas, SP, 1995. Dissertação (Mestrado) - Faculdade de Educação, UNICAMP.

FRANCHI, E. P. Pedagogia da alfabetização da oralidade à escrita. São Paulo : Cortez, 1988.

FREIRE, P. Educação e mudança. Rio de Janeiro : Paz e terra, 1997.

Conscientização : teoria $e$ prática da libertação: uma introdução ao pensamento de Paulo Freire. São Paulo : Moraes, 1980.

Pedagogia do oprimido. Rio de Janeiro: Paz e Terra, 1985.

, MACEDO, D. Alfabetização

: leitura do mundo, leitura da palavra. São Paulo: Paz e Terra, 1990.

GRAFF, H. J. Os labirintos da alfabetização. Porto Alegre: Artes Médicas, 1991.
GOYOS, A. C. N. A profissionalização de deficientes mentais : estudo de verbalização de Professores acerca desta questão. São Paulo, $1986 . \quad$ Tese (Doutorado) - Instituto de Psicologia, USP.

GUANAIS, M. A. B. O trabalho $\boldsymbol{e} \boldsymbol{a}$ Qualidade Total : contribuições do psicólogo organizacional. Campinas,SP,1995. Tese (Mestrado). Faculdade de Educação, UNICAMP..

KLEIN, L. R. Alfabetização : quem tem medo de ensinar? São Paulo : Cortez, 1996.

LUCKESI, C. C. Avaliação educacional escolar : para além do autoritarismo. Tecnologia Educacional, Rio de Janeiro, n.61, p.6-15, 1984.

SIMÃO, L. M. Estudo descritivo de relações professor-aluno : a questão do procedimento de coleta de dados. Psicologia , v.8, n.3, p.37-59, 1982.

SOARES, M. B. Alfabetização : a (des)aprendizagem das funções da escrita. Educação em Revista, Belo Horizonte, n.8, p.3-11, 1988.

cultura : relações, dimensões e perspectivas. Revista Brasileira de Educação, São Paulo, n.0, p.5-11, 1995.

TORRES, C. A. Diálogo com Paulo Freire. São Paulo : Loyola, 1979.

TUNES, E. Identificação da natureza e origem das dificuldades de alunos de pós-graduação, para formularem problemas de pesquisa, através de seus relatos verbais. São Paulo, 1981. Tese 
(Doutorado) - Instituto de Psicologia , USP.

VYGOTSKY, L. S. A formação social da mente. São Paulo : Martins Fontes, 1994

ZANATTO, M. L. B. Ações $\boldsymbol{e}$ representações: uma tentativa de análise das relações de trabalho na escola. São Paulo, 1985. Dissertação (Mestrado) Instituto de Psicologia, USP.

ZANELLI, J. C. Formação profissional e atividades de trabalho : análise das necessidades identificadas por psicólogos organizacionais. Campinas, SP, 1992. Tese (Doutorado) - Faculdade de Educação, UNICAMP.

\section{Sérgio Antônio da Silva Leite} Cíntia Wolf do Amaral

Prof. Dr. e Coordenador do ALLE - Grupo de pesquisa Alfabetização, Leitura, Escrita Faculdade de educação UNICAMP e-mail: aasleite@uol.com.br 